\title{
Detection of magnesium compounds in dietary supplements and medicinal products by DSC, Infrared and Raman techniques
}

\author{
Marek Wesolowski • Edyta Leyk • Piotr Szynkaruk
}

Received: 2 October 2013/Accepted: 14 March 2014/Published online: 11 April 2014

(C) The Author(s) 2014. This article is published with open access at Springerlink.com

\begin{abstract}
The aim of this study was to learn to what extent the selected instrumental techniques, differential scanning calorimetry (DSC), as well as Fourier-transform infrared (FTIR) and Raman spectroscopies, can be used to detect both organic or inorganic magnesium compounds in the dietary supplements and medicinal products. Besides magnesium compounds as the active pharmaceutical ingredients (APIs), the preparations contain also other organic and inorganic APIs and several excipients. The study will be extended over the analysis of the products manufactured by various firms but containing the same API at different levels. In this way, it will be possible to assess the impact of excipients on the DSC scans and the FTIR and Raman spectra of a dominant constituent present in a studied preparation. The study on thirty commercially available dietary supplements and medicinal products has shown that in the majority of cases the DSC, FTIR and Raman techniques could be used for the detection of APIs in these commercial products. This was possible with the aid of the endothermic DSC peaks and the so-called matching factors of the FTIR and Raman spectra to those of substances used as standards. Both the complex composition and low levels of API in the studied preparations have been identified as the factors which have a strong impact on the usefulness of the three techniques for the detection of APIs in the dietary and medicinal products.
\end{abstract}

Keywords Magnesium compounds - DSC · FTIR · Raman · Quality control · Dietary supplements · Medicinal products

M. Wesolowski $(\bowtie) \cdot$ E. Leyk · P. Szynkaruk

Department of Analytical Chemistry, Medical University of

Gdansk, Gen. J. Hallera 107, 80-416 Gdansk, Poland

e-mail: marwes@gumed.edu.pl

\section{Introduction}

Quality evaluation of dietary supplements and medicinal products is mandatory from the point of view of efficacy, safety and stability of these preparations used for prophylactic and therapeutic purposes. Pharmaceutical law requires controlling compatibility of active pharmaceutical ingredients (APIs) and excipients with the appropriate standards $[1,2]$. This obliges the producers to control the quality of all raw materials used in the manufacturing of medicinal products and to screen this process. Also the quality of a final drug product should be monitored. The investigation program comprises, among others, the surveillance of appearance of a pharmaceutical preparation, its labeling, quantitation of API in a dosage form, evaluation of physicochemical properties (hardness, density) and bioavailability of a drug form. Requirements for the quality control of dietary supplements are not so strict as in the case of medicinal products. However, in recent years there are legislation works conducted on the regulations, according to which the process of registration, manufacturing and quality control of dietary supplements should obey the same rules, as those referring to pharmaceuticals.

The necessity of permanent studies of APIs and medicinal products in a solid state is recommended, among others, by the regulations of the International Conference on Harmonization of Technical Requirements for Registration of Pharmaceuticals for Human Use (ICH), issued in the 1990-ties with the best of intentions to unify the requirements for new drugs implemented in the pharmaceutical market [3]. Recommendations of ICH, which are set in the both European and national pharmacopoeias $[1,2]$ oblige the manufacturers of medicinal products to conduct additional studies of all raw materials used in the formulation process. These studies have to encompass the 
polymorphism, determination of crystal properties, particle size and specific surface, hygroscopic properties, solubility and chirality [4].

To perform these examinations, and to confirm the identity of all ingredients used by manufacturers, and also to quantify the dietary supplements and medicinal products, a sound knowledge of the technology of drug formulations and the methodology of drug analysis is necessary $[5,6]$. The intensive progress in science and technology has resulted in introduction of highly advanced instrumental techniques to a modern pharmaceutical analysis. A screening of the literature data has shown that among others, thermoanalytical and spectroscopic techniques can be used to a large extent in the drug and food analysis. Numerous papers published recently revealed some examples of usefulness of differential scanning calorimetry (DSC) [7-11], thermogravimetry (TG) [7, 8, 12, 13], Fourier-transform infrared (FTIR) [10, 13-15], near infrared (NIR) $[11,14,16]$ and Raman $[9,14,17-20]$ techniques for analytical purposes.

For this reason, the aim of this study was to learn, to what extent selected thermoanalytical (DSC) and spectroscopic (FTIR, Raman) techniques could be useful for the evaluation of the composition of commercially available dietary supplements and medicinal products. The objective of the study involved detection of a particular substance in a studied preparation which contained several excipients along with the active substance. The DSC, FTIR and Raman techniques were selected because they enable to obtain quick result from a small sample without a timeconsuming separation of API from a complex matrix. The features of these techniques are crucial from the point of view of quality control in the pharmaceutical industry. Recent tendencies lead to monitor the manufacturing process in the real time, enabling in this way that elimination of the control of a final product [18-21]. This new, original approach to the quality problem in the pharmaceutical industry is called Process Analytical Technology (PAT).

\section{Experimental}

\section{Materials}

A total number of thirty commercially available dietary supplements and medicinal products were analysed. These are as follows (manufacturers given in parentheses): Asmag, Asmag B, Asmag forte (Farmapol, Poznan, Poland); Aspargin, Filomag $\mathrm{B}_{6}$ (Filofarm, Bydgoszcz, Poland); Asparaginum forte $\mathrm{Mg}+\mathrm{K}$ (Polski Lek, Warsaw, Poland); Asparginian extra (Uniphar, Warsaw, Poland); Bio-Magnez (Pharma Nord, Vojens, Denmark); BluMag Jedyny (Hasco-Lek, Wroclaw, Poland); Cardiomin B 6 (Puritan's
Pride, Bohema, USA); Chela-Mag B 6 (Olimp Labs, Debica, Poland); Dipromal $200 \mathrm{mg}$ (ICN Polfa, Rzeszow, Poland); Dolomit VIS (VIS, Bytom, Poland); Laktomag $B_{6}$ (Chance, Czosnow, Poland); Maglek $\mathrm{B}_{6}$ (Lek-Am, Zakroczyn, Poland); Magne $\mathrm{B}_{6}$, Magne $\mathrm{B}_{6} \max$ (SanofiAventis, Rzeszow, Poland); Magnefar $\mathrm{B}_{6}$, Magnefar $\mathrm{B}_{6}$ Cardio (Biofarm, Poznan, Poland); Magnesol 150 (Krka, Novo mesto, Slovenia); Magnezin (Polfa, Grodzisk Mazowiecki, Poland); Magvit $\mathrm{B}_{6}$ (GSK Pharmaceuticals, Poznan, Poland); $\mathrm{Mg} \mathrm{B}_{6}$, NeoMag Cardio, NeoMag forte (Aflofarm, Ksawerow, Poland); Slow-Mag, Slow-Mag B 6 (Curtis Healthcare, Poznan, Poland); and Zdrovit magnez + vit. $B_{6}$, Zdrovit Magnum forte, Zdrovit Skurcz (NP Pharma, Ostrow Mazowiecki, Poland).

The active ingredients used were as follows: $\mathrm{Mg}$ acetate tetrahydrate, $\mathrm{Mg}$ carbonate, $\mathrm{Mg}$ chloride hexahydrate, $\mathrm{Mg}$ hydroxide, $\mathrm{Mg}$ oxide, pyridoxine hydrochloride (POCh, Gliwice, Poland); Mg citrate (Krka, Warsaw, Poland); $\mathrm{Mg}$ hydrogen aspartate tetrahydrate (Novichem, Chorzow, Poland); Mg lactate dihydrate (Sanofi-Biocom, Rzeszow, Poland); $\mathrm{Mg}$ valproate hydrate (ICN Polfa, Rzeszow, Poland); folic acid, tocopherol acetate (Sigma-Aldrich, Saint Louis, USA).

The excipients used were as follows: microcrystalline cellulose, sodium carboxymethyl cellulose (FMC Bio Polymer, Brussels, Belgium); corn starch (Sigma-Aldrich, Saint Louis, USA); ethylcellulose, potato starch, saccharose (MP Biomedicals LLC, Illkirch Cedex, France); lactose (PPH Galfarm, Krakow, Poland); methylcellulose, hydroxypropyl methylcellulose (Shin-Etsu Chemical Co., Tokyo, Japan); Mg stearate (Sinochem, Jiangsu, China); polyvinylpyrrolidone (Fluka, Siegen, Germany); sodium lauryl sulphate (Merck, Darmstadt, Germany); sodium starch glycolate (JRS Pharma, Rosenberg, Germany). All substances were used without further purification.

\section{Methods}

DSC scans were performed on a heat-flux DSC instrument (model 822 $2^{\mathrm{e}}$, Mettler Toledo, Schwerzenbach, Switzerland) with a liquid nitrogen cooling system (Dewar vessel) and a STAR $^{\mathrm{e}}$ software. Samples under study, of approximately $4 \mathrm{mg}$ in mass, were accurately weighed $( \pm 0.01 \mathrm{mg})$ and encapsulated in $40 \mu \mathrm{L}$ flat-bottomed aluminium pans with crimped-on lids. Measurements were carried out over the range between 25 and $300{ }^{\circ} \mathrm{C}$ at a heating rate of $10{ }^{\circ} \mathrm{C} \mathrm{min}{ }^{-1}$ under nitrogen stream at a flux rate of

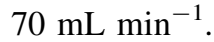

Indium (In) and zinc ( $\mathrm{Zn})$ standards were used to calibrate the DSC cell. Reference values for onset temperature and heat flow with the tolerance limits were as follows: $156.6 \pm 0.3{ }^{\circ} \mathrm{C}$ and $28.45 \pm 0.6 \mathrm{~J} \mathrm{~g}^{-1}$ for In; $419.6 \pm 0.7^{\circ} \mathrm{C}$ and $107.5 \pm 3.2 \mathrm{~J} \mathrm{~g}^{-1}$ for $\mathrm{Zn}$, whereas the 
measured ones: $156.6{ }^{\circ} \mathrm{C}$ and $28.80 \mathrm{~J} \mathrm{~g}^{-1}$ (In); $420.1{ }^{\circ} \mathrm{C}$ and $110.7 \mathrm{~J} \mathrm{~g}^{-1}(\mathrm{Zn})$. Calibration and all the necessary adjustments were performed with aid of the computer program Calib DSC Total In/Zn (Mettler Toledo, Schwerzenbach, Switzerland).

FTIR spectra were recorded on a Nicolet 380 FTIR spectrometer (Thermo Fischer Scientific, Madison, USA) with a DTGS $\mathrm{KBr}$ detector and an OMNIC software. The analysed samples were prepared as $\mathrm{KBr}$ pellets with the aid of a hydraulic press (Specac, Orpington, UK). Each pellet was prepared from a 1-mg sample and $100 \mathrm{mg}$ of a spectroscopy-grade $\mathrm{KBr}$ (Merck, Darmstadt, Germany). Measurements were carried out over the spectral range of $4,000-400 \mathrm{~cm}^{-1}$ with spectral resolution of $4 \mathrm{~cm}^{-1}$ Before each measurement, background spectra were taken with average 16 scans.

Raman spectra were recorded on a DXR SmartRaman spectrometer (Thermo Fisher Scientific, Madison, USA). The spectrometer was equipped with a $15-\mathrm{mW}$ DXR $780 \mathrm{~nm}$ laser with a slit width of $25 \mu \mathrm{m}$, Raleigh filter, CCD detector and an OMNIC software. The measurements were run over the range of 3,413-99 $\mathrm{cm}^{-1}$. Exposure time was $1 \mathrm{~s}$ (twice). DSC, FTIR and Raman experiments were repeated at least in triplicate.

\section{Results and discussion}

To check the utility of DSC, FTIR and Raman techniques as a potential approach enabling detection of a drug substance in dietary supplements and medicinal products, thirty preparations commonly available in Poland were chosen. Mg salts of organic acids (acetate, citrate, diglycinate, hydrogen aspartate, lactate, valproate) and inorganic $\mathrm{Mg}$ compounds (carbonate, chloride, hydroxide, oxide) were present in the studied preparations as dominant active ingredients. Furthermore, some preparations also containing varying amounts of other organic and inorganic salts of potassium (aspartate, citrate, gluconate, hydrogen aspartate, bicarbonate, chloride) and of calcium (citrate, hydrogen aspartate, carbonate). Organic APIs, such as pyridoxine hydrochloride (vitamin $\mathrm{B}_{6}$ ), aspartic and folic acids and tocopherol acetate were also present in some samples. Merely eleven preparations (Asmag, Asmag forte, Asparagin, Asparaginum forte $\mathrm{Mg}+\mathrm{K}$, Asparginian extra, Bio-Magnez, Dipromal 200 mg, Dolomit VIS, Magnesol 150, Magnezin, Slow-Mag) did not contain vitamin $\mathrm{B}_{6}$.

Fourteen out of thirty preparations were medicinal products containing $\mathrm{Mg}$ salts of organic acids as APIs. These were: Asmag, Asmag B, Asmag forte, Aspargin, Dipromal $200 \mathrm{mg}$, Filomag $\mathrm{B}_{6}$, Laktomag $\mathrm{B}_{6}$, Maglek $\mathrm{B}_{6}$, Magvit $\mathrm{B}_{6}$ and Magne $\mathrm{B}_{6}$, whereas Dolomit VIS, Magnezin, Slow-Mag and Slow-Mag $\mathrm{B}_{6}$ including inorganic $\mathrm{Mg}$ compounds. Medicinal products under study constitute the so-called over-the-counter (OTC) drugs.

The majority of dietary and medicinal products were in the form of tablets. The remaining ones were in coated tablets (Cardiomin $\mathrm{B}_{6}$, Dipromal $200 \mathrm{mg}$, Magne $\mathrm{B}_{6} \max$, $\mathrm{Mg} \mathrm{B}_{6}$, NeoMag Cardio, NeoMag forte, Zdrovit Skurcz), gastro-resistant tablets (Magne $\mathrm{B}_{6}$, Magvit $\mathrm{B}_{6}$, Slow-Mag, Slow-Mag $\mathrm{B}_{6}$ ) and effervescent tablets (Magnesol 150, Zdrovit magnez + vit. $\mathrm{B}_{6}$, Zdrovit Magnum forte). Moreover, two dietary supplements were in the form of capsules (Chela-Mag $\mathrm{B}_{6}$, BluMag Jedyny). Hence, all the preparations studied included various numbers and quantities of excipients, ensuring optimal activity of the dosage forms from the point of view of pharmacotherapy. Chemical analysis includes usually separation of APIs from excipient this being a time- and work-consuming process. Hopefully, application of DSC, FTIR, and Raman techniques could allow for elimination of this step of analytical procedure.

\section{Differential scanning calorimetry}

DSC is a thermoanalytical technique where energy changes in a sample are monitored with temperature [6]. The heat flow to or from the sample and to or from the reference is monitored as a function of temperature or time. Such measurements provide qualitative and quantitative information about physical and chemical changes involving endothermic and exothermic processes, or changes in heat capacity, i.e., thermal transformations. These features of the DSC were used for the study of thirty dietary supplements and medicinal products and dominant constituents present in these preparations. The DSC scans of the drug substances are shown in Fig. 1, while the data characterising their thermal behaviour over the temperature range of $25-300{ }^{\circ} \mathrm{C}$

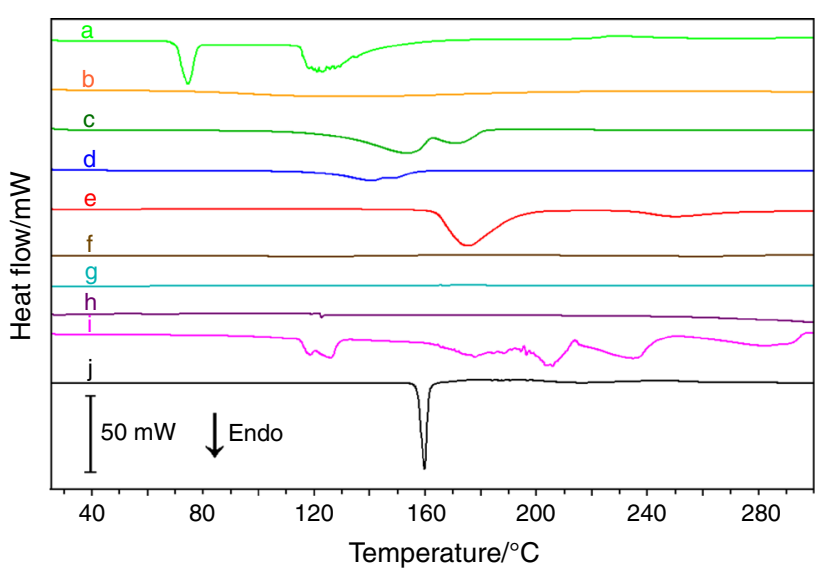

Fig. 1 DSC scans of magnesium (a) acetate tetrahydrate, $(b)$ citrate, $(c)$ lactate dihydrate, $(d)$ valproate, $(e)$ hydrogen aspartate tetrahydrate, $(f)$ oxide, $(g)$ hydroxide, $(h)$ carbonate, $(i)$ chloride hexahydrate and $(j)$ pyridoxine hydrochloride 
Table 1 Active ingredients included in the studied dietary supplements and medicinal products

\begin{tabular}{|c|c|c|c|c|}
\hline No. & Active ingredients & Thermal process $[22,23]$ & Endothermic DSC peak $/{ }^{\circ} \mathrm{C}$ & Heat of transition $/ \mathrm{J} \mathrm{g}^{-1}$ \\
\hline \multirow[t]{2}{*}{1} & \multirow[t]{2}{*}{ Magnesium acetate tetrahydrate } & $80{ }^{\circ} \mathrm{C}$ dehydration & 73.24 & 178.39 \\
\hline & & $323{ }^{\circ} \mathrm{C}$ decomposition & 121.67 & 376.36 \\
\hline 2 & Magnesium citrate & - & 130.78 & 467.90 \\
\hline \multirow[t]{2}{*}{3} & \multirow[t]{2}{*}{ Magnesium lactate dihydrate } & \multirow[t]{2}{*}{-} & 152.26 & 270.48 \\
\hline & & & 171.68 & 91.64 \\
\hline \multirow[t]{2}{*}{4} & \multirow[t]{2}{*}{ Magnesium valproate hydrate } & \multirow[t]{2}{*}{-} & 139.33 & 35.66 \\
\hline & & & 148.89 & 11.95 \\
\hline 5 & Magnesium hydrogen aspartate tetrahydrate & - & 173.83 & 579.34 \\
\hline 6 & Magnesium oxide & $2,800{ }^{\circ} \mathrm{C}$ melting & - & - \\
\hline 7 & Magnesium hydroxide & $350{ }^{\circ} \mathrm{C}$ dehydroxylation & - & - \\
\hline 8 & Magnesium carbonate & $350{ }^{\circ} \mathrm{C}$ decarboxylation & - & - \\
\hline \multirow[t]{2}{*}{9} & \multirow[t]{2}{*}{ Magnesium chloride hexahydrate } & \multirow[t]{2}{*}{$116-118{ }^{\circ} \mathrm{C}$ dehydration } & 117.49 & 154.38 \\
\hline & & & 196.66 & 182.06 \\
\hline 10 & Pyridoxine hydrochloride & $160{ }^{\circ} \mathrm{C}$ melting with decomposition & 157.11 & 211.81 \\
\hline
\end{tabular}

are listed in Table 1 . These data revealed that with the exception of $\mathrm{Mg}$ chloride hexahydrate, all the remaining inorganic Mg compounds (oxide, hydroxide, carbonate) did not undergo any thermal transformation over the range studied [22]. Because $\mathrm{MgO}$ melts at 2,800 ${ }^{\circ} \mathrm{C}, \mathrm{Mg}(\mathrm{OH})_{2}$ dehydroxylates and $\mathrm{MgCO}_{3}$ decarboxylates above $350{ }^{\circ} \mathrm{C}$, there are no DSC peaks between 25 and $300{ }^{\circ} \mathrm{C}$ that can be used for the detection of dominant compounds in the dietary and medicinal products. In this case the DSC scans can be used for detection the organic active substances, e.g., vitamin $\mathrm{B}_{6}$, organic salts of magnesium, potassium and calcium or excipients, e.g., saccharose, lactose, microcrystalline cellulose. Merely $\mathrm{MgCl}_{2} \cdot 6 \mathrm{H}_{2} \mathrm{O}$ is characterised by several endothermic DSC peaks owing to its step-by-step dehydration.

Thermal decomposition of Mg salts of organic acids has been studied previously [23]. The results have shown that the evolution of crystallization water takes place in the range between 35 and $255^{\circ} \mathrm{C}$ for $\mathrm{Mg}$ acetate, $\mathrm{Mg}$ lactate, $\mathrm{Mg}$ valproate and $\mathrm{Mg}$ hydrogen aspartate. TG curves revealed that $\mathrm{Mg}$ valproate and $\mathrm{Mg}$ hydrogen aspartate dehydrate in one stage while dehydration of $\mathrm{Mg}$ acetate and $\mathrm{Mg}$ lactate comprised three and two stages, respectively. These findings were confirmed by endothermic DSC peaks in Fig. 1, scans a, c-e. An exception to this scheme is $\mathrm{Mg}$ citrate which is characterised by a shallow endothermic peak over the range of 73 and $181{ }^{\circ} \mathrm{C}$ peaked at $131{ }^{\circ} \mathrm{C}$ (scan b). Hence, in the case of $\mathrm{Mg}$ salts of organic acids and pyridoxine hydrochloride, strong and sometimes narrow endothermic DSC peaks would constitute a basic criterion for the detection of these substances.

Results acquired from the DSC scans of thirty dietary and medicinal products are compiled in Table 2. Their preliminary inspection has shown a strong impact of the quantity of active ingredients based on the mass unit of a tablet on the ability to identify an API in a preparation. The data in Table 2 calculated on the basis of the dose of an active substance and the mean tablet mass designed for 10 units of tablets have shown that the preparations can be differentiated by the percentage contents of an API. Generally, the dietary supplements and medicinal products contained higher amounts of $\mathrm{Mg}$ salts of organic acids ( $\sim 50-90 \%$ of the tablet mass) than inorganic compounds, with the exception of the dietary supplement BluMag Jedyny. It contains more than $93 \%$ of $\mathrm{MgO}$ per tablet mass.

For the majority of preparations under study, manufacturers provide information on the content of $\mathrm{Mg}$ compounds recalculated as $\mathrm{Mg}^{2+}$ ions, regardless of the fact that some of them contain two or three $\mathrm{Mg}$ compounds. For instance, for Bio-Magnez the content of $\mathrm{Mg}$ acetate, $\mathrm{MgCO}_{3}$ and $\mathrm{Mg}(\mathrm{OH})_{2}$ is given as $19.9 \%$ of $\mathrm{Mg}^{2+}$ ions while Cardiomin B6 comprising $\mathrm{Mg}$ hydrogen aspartate, $\mathrm{Mg}$ citrate and $\mathrm{MgO}$ is labeled as containing $12.4 \%$ of $\mathrm{Mg}^{2+}$ ions. For this reason, it is impossible the precisely define the percentage of each constituent in a particular preparation.

Interpretation of the DSC scans of all dietary supplements and medicinal products revealed that endothermic peaks due to the dehydration of $\mathrm{Mg}$ salts can be used for the detection of APIs in the studied samples. This can be exemplified by a DSC scan of the drug Dipromal $200 \mathrm{mg}$ (Fig. 2) which shows the presence of $\mathrm{Mg}$ valproate in the sample as compared to the scan of $\mathrm{Mg}$ valproate used as a standard. Similarly, in the DSC scan of the dietary supplement Bio-Magnez there is an endothermic peak 


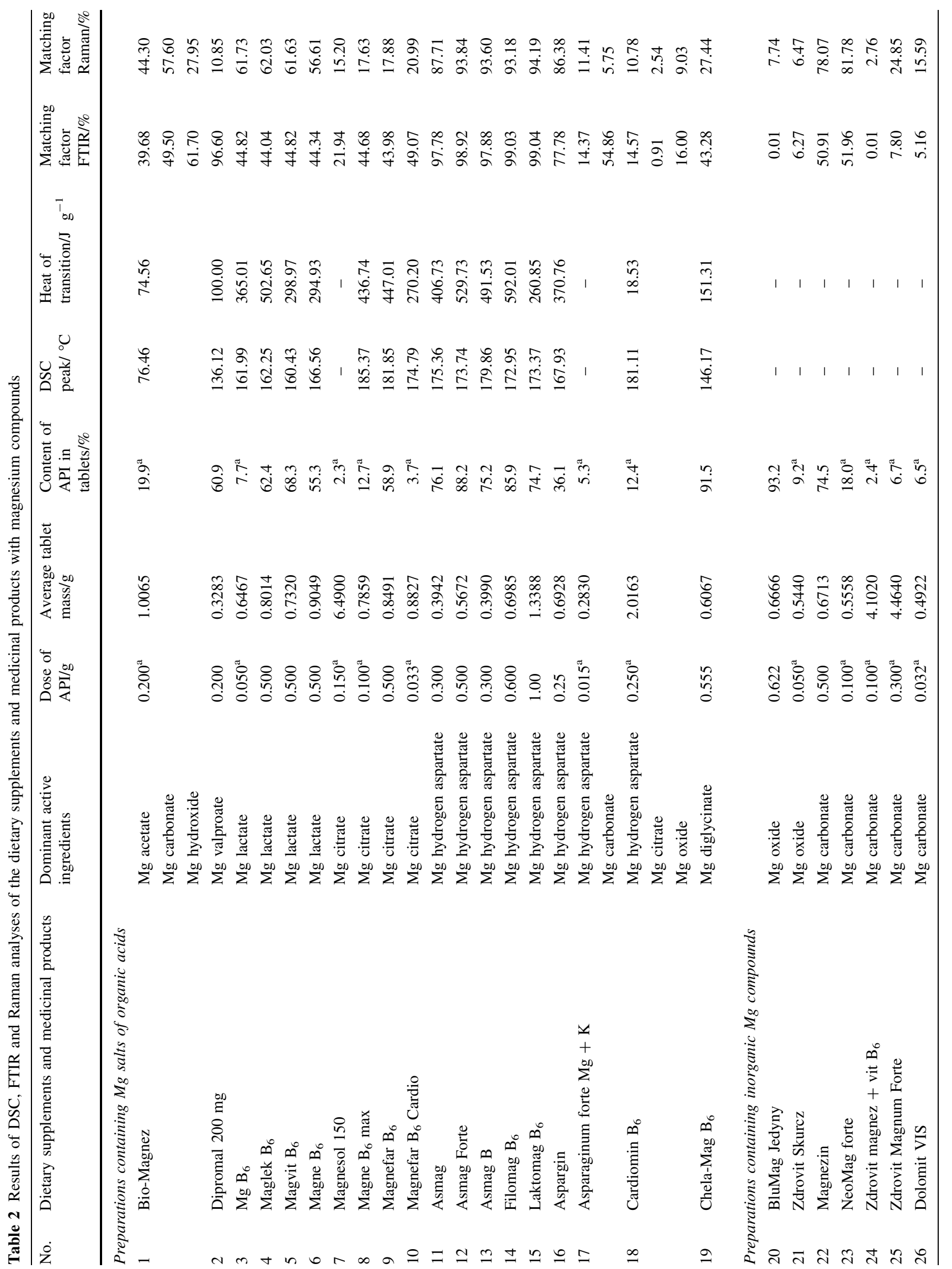




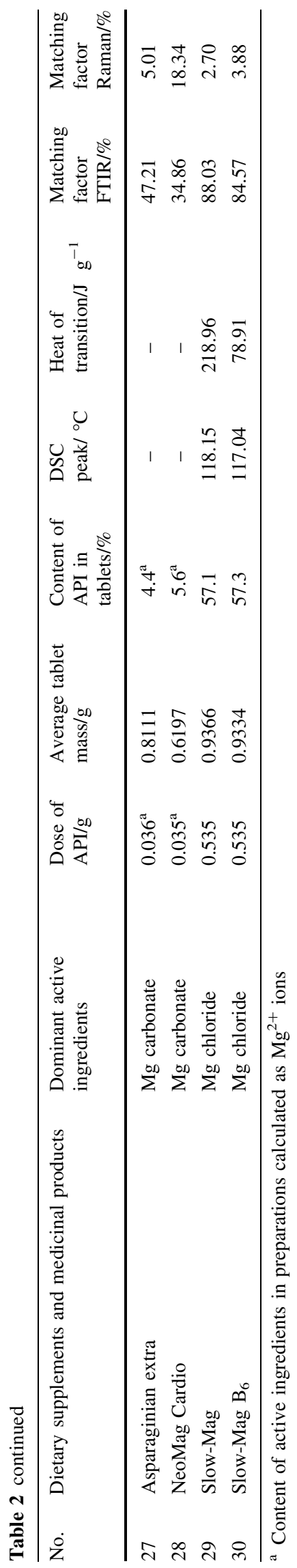

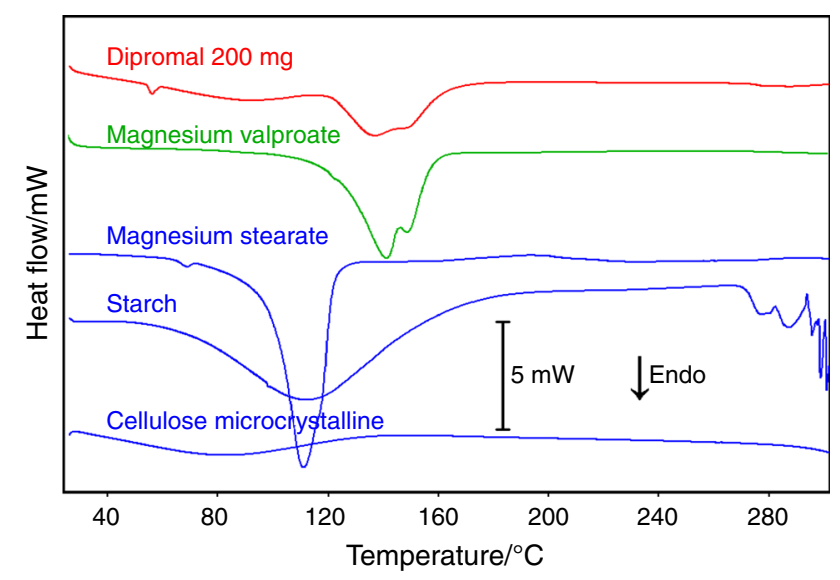

Fig. 2 DSC scans of medicinal product Dipromal $200 \mathrm{mg}$; magnesium valproate as API; and excipients

assigned to the dehydration of $\mathrm{Mg}$ acetate (Table 2). Other active ingredients, $\mathrm{MgCO}_{3}$ and $\mathrm{Mg}(\mathrm{OH})_{2}$, did not undergo any thermal processes over the temperature range studied.

Four dietary and medicinal products: $\mathrm{MgB}_{6}$, Maglek $\mathrm{B}_{6}$, Magvit $\mathrm{B}_{6}$ and Magne $\mathrm{B}_{6}$ contain almost identical quantities of APIs (Mg lactate and pyridoxine hydrochloride) but they are produced by different manufacturers, and due to this they differ by the kind and quantities of excipients. Their DSC scans display strong, broad peaks between 125 and $175{ }^{\circ} \mathrm{C}$ which confirm the presence of $\mathrm{Mg}$ lactate. There is no clear-cut signal originating from vitamin $\mathrm{B}_{6}$ because it is present as a minor constituent $(5-6 \mathrm{mg})$. DSC scans of other dietary supplements: Magne $B_{6}$ max, Magnefar $\mathrm{B}_{6}$ and Magnefar $\mathrm{B}_{6}$ Cardio clearly reflect dehydration of $\mathrm{Mg}$ lactate that enables its identification. However, there is no endothermic peak assignable to $\mathrm{Mg}$ lactate in a scan of Magnesol 150 tablets. Probably, thermal effects caused by a violent reaction between effervescent agents, sodium bicarbonate and citric acid, with releasing of carbon dioxide, preclude identification of characteristic DSC peaks of its dehydration.

Similar to $\mathrm{Mg}$ citrate and $\mathrm{Mg}$ lactate, high levels of $\mathrm{Mg}$ hydrogen aspartate in the tablets of Asmag, Asmag Forte, Asmag B, Filomag $\mathrm{B}_{6}$, Laktomag $\mathrm{B}_{6}$ and Aspargin (medicinal products) enable easy detection of this salt by a large endothermic DSC peak due to the dehydration of API (Table 2). The dietary supplements: Asparaginum forte $\mathrm{Mg}+\mathrm{K}$ and Cardiomin $\mathrm{B}_{6}$ also contain $\mathrm{Mg}$ hydrogen aspartate, but their composition is more complex. In the former case, there are calcium carbonate and potassium hydrogen aspartate and chloride, while the latter sample contains also $\mathrm{Mg}$ citrate and $\mathrm{MgO}$, potassium hydrogen aspartate, gluconate and citrate, and calcium hydrogen aspartate, citrate and oxide. For this reason, the DSC scans show small peaks of a low intensity which are difficult for interpretation. There are no clear-cut signals originating 


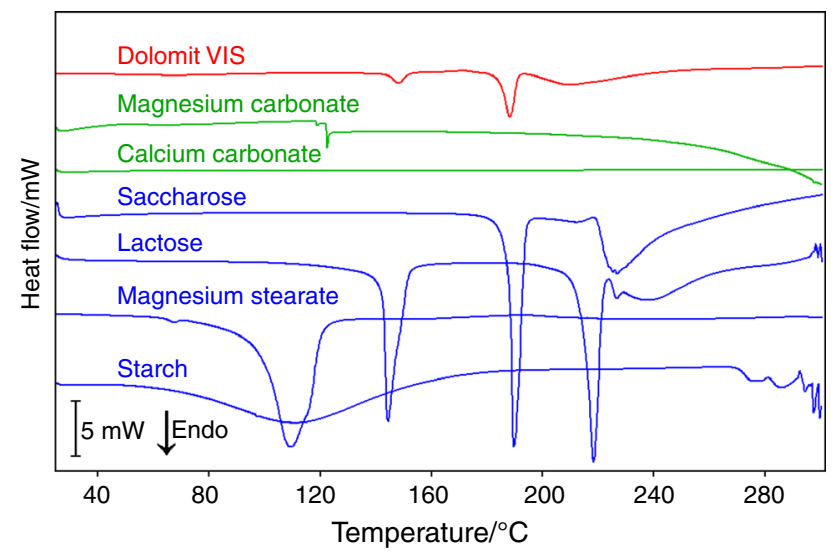

Fig. 3 DSC scans of medicinal product Dolomit VIS; magnesium carbonate and calcium carbonate as APIs; and excipients

from $\mathrm{Mg}$ compounds present in the preparations as dominating ingredients.

Another group of dietary and medicinal products contains inorganic $\mathrm{Mg}$ compounds as APIs. Active substances comprised in the dietary supplements BluMag Jedyny and Zdrovit Skurcz $(\mathrm{MgO})$ and in the tablets of Magnezin, NeoMag forte, Zdrovit magnez + vit $\mathrm{B}_{6}$, Zdrovit Magnum Forte, Dolomit VIS, Asparaginian extra, NeoMag Cardio, Slow-Mag and Slow-Mag $\mathrm{B}_{6}\left(\mathrm{MgCO}_{3}\right)$ could not be identified by DSC because endothermic peaks assignable to $\mathrm{MgO}$ and $\mathrm{MgCO}_{3}$ were missing. As shown in Fig. 3 (Dolomit VIS), small endothermic DSC peaks are due to the melting of excipients, lactose $\left(\sim 143{ }^{\circ} \mathrm{C}\right)$ and saccharose $\left(\sim 189^{\circ} \mathrm{C}\right)$. On the other hand, the DSC scans of Slow-Mag and Slow-Mag $\mathrm{B}_{6}$ indicated that $\mathrm{MgCl}_{2} \cdot 6 \mathrm{H}_{2} \mathrm{O}$ could be easily identified in the medicinal products based on characteristic endothermic DSC peaks due to dehydration.

\section{Infrared and Raman spectroscopy}

Infrared (IR) and Raman spectroscopies are vibrational techniques [6]. They are non-destructive and extremely useful for providing structural information about molecules in terms of their functional groups, the orientation of those groups and information on isomers. In association with chemometric methods they can also be used to provide quantitative information [14-16]. IR and Raman spectroscopies are similar insofar as they both produce spectra based on vibrational transitions within a molecule and use the same spectral regions [6]. They differ in the way that the observation and measurement are achieved, since IR is an absorption (transmission) method, while Raman is a scattering method. The use of an interferometer to obtain the IR spectra caused that a FTIR spectrometer has become a commonly used instrument in scientific and industrial pharmaceutical labs. The advantages of FTIR are greater sensitivity (signal-to-noise ratio) owing to the use of certain detectors and a greater speed owing to simultaneous acquisition of data (simultaneous measurement at all wavelengths).

The FTIR spectra of the drug substances taken over the range of $4,000-400 \mathrm{~cm}^{-1}$ (Fig. 4) consist of a complex series of sharp peaks corresponding to the vibrations of spectral groups within the molecule. Two spectral ranges, $3,600-2,800 \mathrm{~cm}^{-1}$ and $1,800-1,000 \mathrm{~cm}^{-1}$, were chosen for interpretation [15]. The fingerprint region $(1,800$ $1,000 \mathrm{~cm}^{-1}$ ) is most valuable because it is partially devoid of absorption bands arising from excipients, and thus enables a better recognition of changes in the structure of the $\mathrm{Mg}$ salts. The region is complemented by bands extending from 3,600 to $2,800 \mathrm{~cm}^{-1}$, frequently highlighting the presence of the $\mathrm{N}-\mathrm{H}, \mathrm{C}-\mathrm{H}$ and $\mathrm{O}-\mathrm{H}$ bounds in the molecule. In this area, characteristic bands of the $\mathrm{O}-\mathrm{H}$ and $\mathrm{C}-\mathrm{H}$ stretching vibrations are observed when carbohydrates (glucose, lactose, saccharose, starch, cellulose) are used as excipients. The literature data on the characteristic IR absorption frequencies of common functional groups were used for assigning bands observed in a spectrum of a $\mathrm{Mg}$ compound to chemical groups in this drug substance [14, 24, 25].

FTIR analysis was conducted of dietary and medicinal products containing $\mathrm{Mg}$ compounds and several excipients. By comparing these spectra with those in Fig. 4, it can be stated that despite complex chemical composition of the studied samples their spectra were the consequences of vibrational transitions within the molecule of a dominant constituent that is a $\mathrm{Mg}$ salt of organic acid. For example,

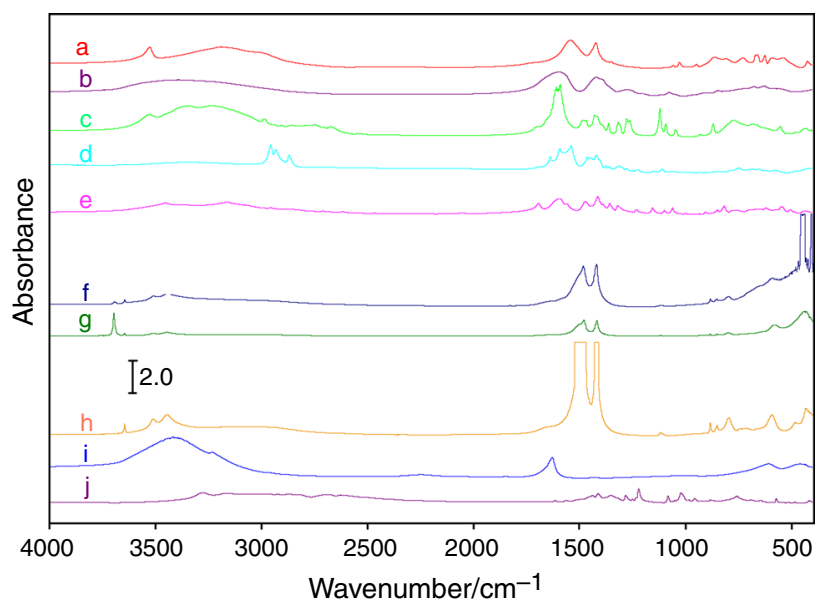

Fig. 4 FTIR spectra of magnesium (a) acetate tetrahydrate, (b) citrate, $(c)$ lactate dihydrate, $(d)$ valproate, $(e)$ hydrogen aspartate tetrahydrate, $(f)$ oxide, $(g)$ hydroxide, $(h)$ carbonate, $(i)$ chloride hexahydrate and $(j)$ pyridoxine hydrochloride 


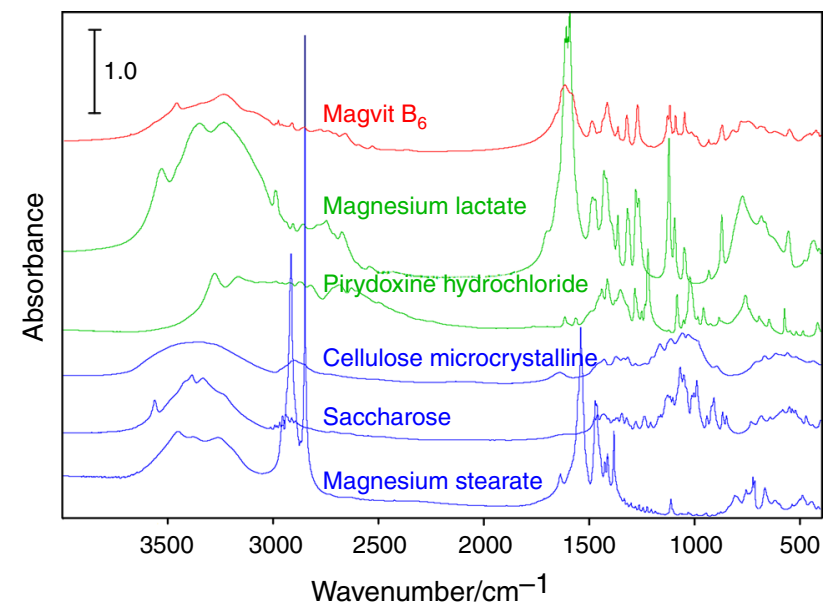

Fig. 5 FTIR spectra of medicinal product Magvit $B_{6}$ containing magnesium lactate and pyridoxine hydrochloride as APIs and excipients

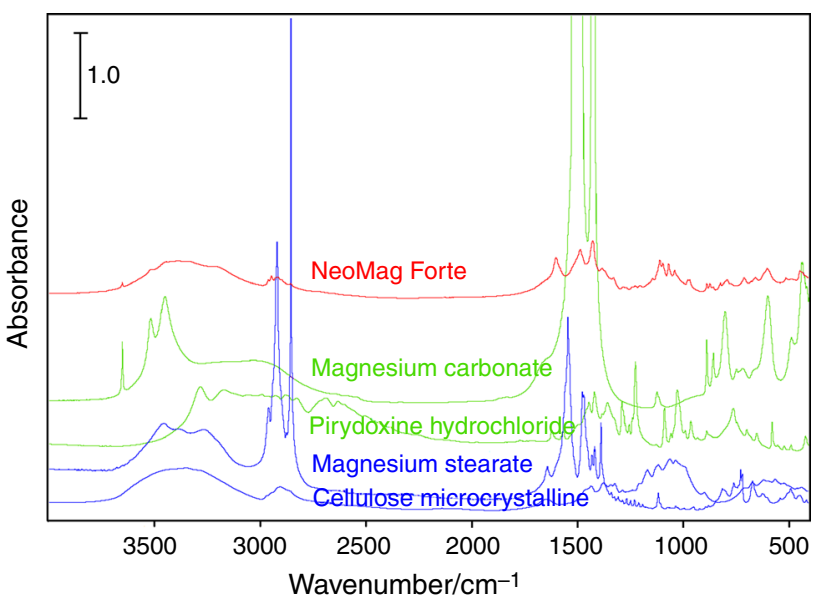

Fig. 6 FTIR spectra of dietary supplement NeoMag Forte containing magnesium carbonate and pyridoxine hydrochloride as APIs and excipients

the spectrum of Magvit $\mathrm{B}_{6}$ shows a close similarity to that of $\mathrm{Mg}$ lactate (Fig. 5). The small difference in the shape of both spectra probably results from the excipients present. On the other hand, there is no similarity between the FTIR spectra of inorganic $\mathrm{Mg}$ compounds and those of the dietary supplements and medicinal products containing these substances. This is presumably due to the lack of characteristic and strong peaks corresponding to the vibrations of spectral groups within the $\mathrm{MgO}$ molecule (Fig. 4, spectra $\mathrm{f}$ and g). An exception provides some tablets containing $\mathrm{MgCO}_{3}$ and $\mathrm{MgCl}_{2} \cdot 6 \mathrm{H}_{2} \mathrm{O}$. As shown in Fig. 6, the spectrum of the NeoMag Forte tablets reflects the presence of $\mathrm{MgCO}_{3}$ in this dietary supplement. The same conclusions can be drawn for the gastro-resistant tablets, Slow-Mag and Slow-Mag $\mathrm{B}_{6}$. In the latter case, apart from $\mathrm{MgCl}_{2} \cdot 6 \mathrm{H}_{2} \mathrm{O}$, vitamin $\mathrm{B}_{6}$ is also present in the tablets.
Taking all above into consideration, the so-called matching factor was designed, which determines in percents the extent of matching of the spectrum of a studied preparation to that of the $\mathrm{Mg}$ salt. This was the basis for confirmation of the presence of active ingredients in the analysed preparations. The computer-generated matching factors for all the dietary and medicinal products are listed in Table 2. The data show that for Mg hydrogen aspartate, which is a dominant constituent in six medicinal products, the matching coefficients of FTIR spectra of the drug products with this salt to the spectrum of $\mathrm{Mg}$ hydrogen aspartate fall within the range of 97.78-99.04\%. An exception provides the matching factor for the Aspargin which is lower (about $78 \%$ ). This indicates that the spectra of these preparations nearly overlap that of $\mathrm{Mg}$ hydrogen aspartate. The close similarity to the spectrum of $\mathrm{Mg}$ valproate also show the tablets of Dipromal $200 \mathrm{mg}$ $(96.60 \%)$, whereas the matching factors of the spectra for preparations comprising $\mathrm{Mg}$ lactate and $\mathrm{Mg}$ citrate to the FTIR spectra of these constituents fall in the range of $44.04-44.82 \%$ and of $43.98-49.07 \%$, respectively. In the latter case, the matching factor for the effervescent tablets of Magnesol 150 was about $22 \%$, thus being of no practical importance from the point of detection of the constituent in this dietary supplement.

With the exception of some preparations with $\mathrm{MgCO}_{3}$, such as the Bio-Magnez, Asparaginum forte $\mathrm{Mg}+\mathrm{K}$, Magnezim, NeoMag Forte, Asparaginian extra and NeoMag Cardio, the matching factors for FTIR spectra of the other tablets with $\mathrm{MgCO}_{3}$ or $\mathrm{MgO}$ in relation to these constituents as the reference are generally low, varying between 0.01 and $16.00 \%$. This suggests that similar to the effervescent tablets of Magnesol 150, effervescent agents present in the tablets of Zdrovit magnez + vit. $\mathrm{B}_{6}$ and Zdrovit Magnum forte, and some of the excipients in the tablets of Dolomit VIS cause that their spectra differ significantly from those of $\mathrm{MgCO}_{3}$ used for comparison, precluding its identification.

Raman spectroscopy is complementary to the IR and is primarily a non-contact quantitative technique [6]. Polar functional groups with low symmetry generally give strong IR signals while molecules with polarisable functional groups with high symmetry generally give strong Raman signals. Hence, strong IR absorptions appear usually as weak Raman ones and vice versa. Moreover, the Raman technique is not as sensitive to the environment of the molecule as is IR. For this reason, Raman spectra for thirty dietary and medicinal products were acquired over the spectral range of 3,413-99 $\mathrm{cm}^{-1}$ together with those of $\mathrm{Mg}$ compounds present in these products. The spectra in Fig. 7 show that organic fragments of $\mathrm{Mg}$ compounds (spectra a-e) and vitamin $B_{6}$ (spectrum $\mathrm{j}$ ) generate Raman frequencies for their characteristic functional groups which can be used for 


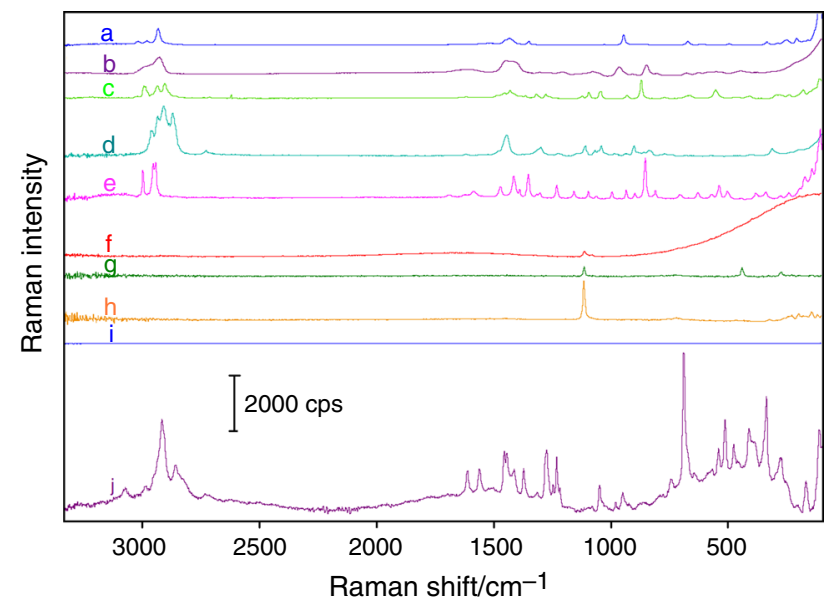

Fig. 7 Raman spectra of magnesium (a) acetate tetrahydrate, (b) citrate, $(c)$ lactate dihydrate, $(d)$ valproate, $(e)$ hydrogen aspartate tetrahydrate, $(f)$ oxide, $(g)$ hydroxide, $(h)$ carbonate, $(i)$ chloride hexahydrate and $(j)$ pyridoxine hydrochloride

the detection of the dominant ingredients in the studied samples [14, 25]. On the other hand, Raman spectra of inorganic $\mathrm{Mg}$ compounds are not characteristic because particular Raman signals associated with different vibrational or rotational motions of the molecules in the sample have either low intensity (spectra $\mathrm{f}, \mathrm{g}$ ) or are missing at all (spectrum i). This is inconvenient from the point of view of identification of $\mathrm{Mg}$ compounds. Merely $\mathrm{Mg}$ carbonate (spectrum h) has an intensive Raman signal which can be used for the detection of this salt.

Data in Table 2 show that with $\mathrm{Mg}$ hydrogen aspartate and $\mathrm{Mg}$ lactate, which are the dominant constituents in the preparations, the matching coefficients of particular Raman spectra of the medicinal products to the spectra of these salts fall within the range of 86.38-94.19\% and $56.61-62.03 \%$, respectively. This indicates that the spectra of the preparations nearly overlap those of $\mathrm{Mg}$ hydrogen aspartate and $\mathrm{Mg}$ lactate. The closest similarity to the spectrum of $\mathrm{Mg}$ hydrogen aspartate shows the tablets of Laktomag $\mathrm{B}_{6}$, but despite the relatively low quantity of this salt in the tablets of Aspargin (36.1\%), the matching factor of the spectrum for this preparation to the Raman spectrum of $\mathrm{Mg}$ hydrogen aspartate exceeds $77 \%$. Also, owing to the complex composition of the Asparaginum forte $\mathrm{Mg}+\mathrm{K}$ and Cardiomin $\mathrm{B}_{6}$ tablets, similarly as in the case of DSC and FTIR results, the presence of Mg hydrogen aspartate and others drug substances in these dietary supplements is reflected by low matching factors. Furthermore, the matching factors for the dietary supplements containing $\mathrm{Mg}$ citrate fall in the range of 15.20-20.99\% which are of no practical importance for the detection of this constituent. As shown in Table 2, a similar conclusion can be drawn for the Dipromal $200 \mathrm{mg}$ tablets.

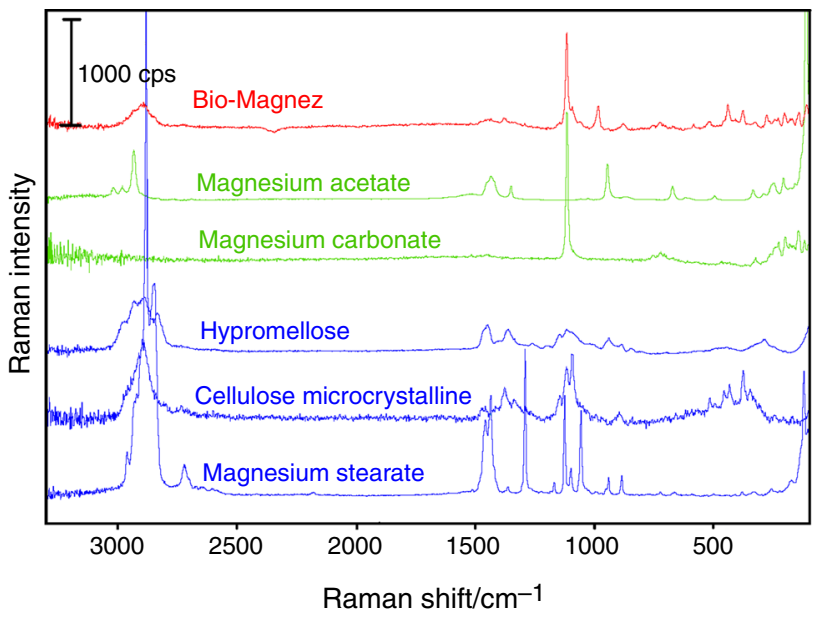

Fig. 8 Raman spectra of dietary supplement Bio-Magnez containing magnesium acetate, magnesium carbonate and magnesium hydroxide as APIs and excipients

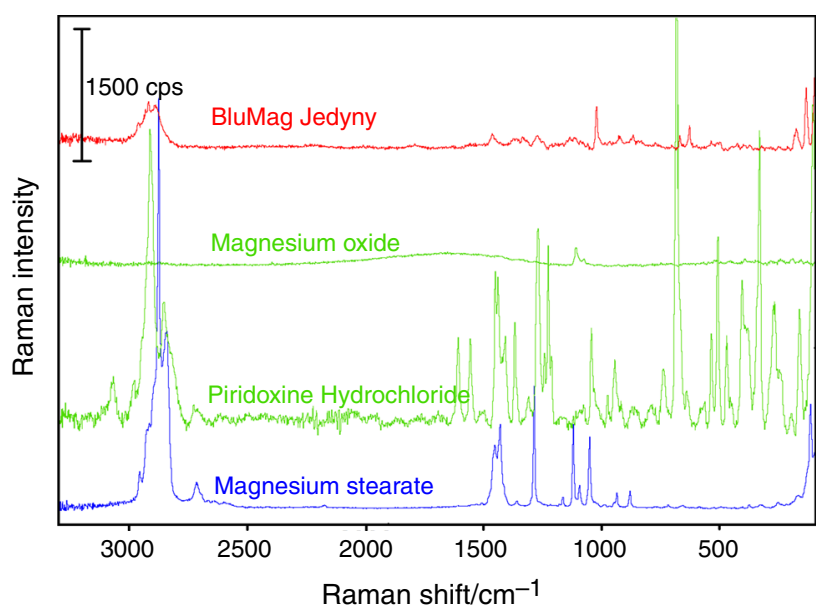

Fig. 9 Raman spectra of dietary supplement BluMag Jedyny containing magnesium oxide and pyridoxine hydrochloride as APIs and excipients

The matching factors of the Raman spectrum of the BioMagnez tablets in relation to those of $\mathrm{Mg}$ acetate, $\mathrm{MgCO}_{3}$ and $\mathrm{Mg}(\mathrm{OH})_{2}$ give the values partially comparable to those obtained by the FTIR technique (Table 2). As shown in Fig. 8 (Bio-Magnez), the presence of $\mathrm{Mg}$ acetate and $\mathrm{MgCO}_{3}$ could be detected in the dietary supplement based on its Raman spectrum. With the exception of the Magnezin and NeoMag forte tablets, for which the matching factors were, respectively, 78.07 and $81.78 \%$, the presence of $\mathrm{MgO}$ (Fig. 9), $\mathrm{MgCO}_{3}$ and $\mathrm{MgCl}_{2} \cdot 6 \mathrm{H}_{2} \mathrm{O}$ in the other preparations could not be confirmed by the matching factors of the Raman spectra of these preparations in spite of a high content of the dominant constituents. 


\section{Conclusions}

This study has shown that in the majority of cases, the DSC, FTIR and Raman techniques could be used for the detection of the dominant constituent in the dietary supplements and medicinal products. A strong impact on the detection ability of these techniques has the content of $\mathrm{Mg}$ compounds used as APIs. To identify the dominant constituents the well-shaped endothermic DSC peaks due to the dehydration of $\mathrm{Mg}$ compounds and the matching factors of the FTIR and Raman spectra to those of Mg compounds (reference substances), were used. The results obtained by the FTIR and Raman spectroscopies were complementary to those obtained by DSC. Furthermore, the way of performing the measurements by these techniques is simple and does not require preliminary preparation of a sample for analysis.

Open Access This article is distributed under the terms of the Creative Commons Attribution License which permits any use, distribution, and reproduction in any medium, provided the original author(s) and the source are credited.

\section{References}

1. European Pharmacopoeia 7. Strasbourg: Council of Europe; 2010.

2. Polish Pharmacopoeia IX. Vol. 1, Warsaw: Ministry of Health; 2011.

3. International Conference on Harmonization of Technical Requirements for Registration of Pharmaceuticals for Human Use. ICH. http://www.ich.org/home.htlm. Accessed Sept 2013.

4. ICH Quality Guidelines. Q6A Specifications: Test procedures and acceptance criteria for new drug substances and new drug products: chemical substances. http://www.ich.org/home.htlm. Accessed Sept 2013.

5. Adeyeye MCh, Brittain HG, editors. Preformulation in solid dosage form development. New York: Informa Healthcare; 2008.

6. McMahon G. Analytical instrumentation. A quide to laboratory, portable and miniaturized Instruments. Chichester: Wiley; 2007.

7. Saunders M. Thermal analysis of pharmaceuticals. In: Gabbott $P$, editor. Principles and applications of thermal analysis. Oxford: Blackwell Publishing; 2008. p. 286-329.

8. Craig DQM, Reading M, editors. Thermal analysis of pharmaceuticals. Boca Raton: CRC Press; 2007.
9. Li Y, Chow PS, Tan RBH. Quantification of polymorphic impurity in an enantiotropic polymorph system using differential scanning calorimetry, X-ray powder diffraction and Raman spectroscopy. Int J Pharm. 2011;415:110-8.

10. Murphy SH, Leeke GA, Jenkins MJ. A comparison of the use of FTIR spectroscopy with DSC in the characterization of melting and crystallization in polycaprolactone. $\mathrm{J}$ Therm Anal Calorim. 2012;107:669-74.

11. Kiss D, Zelkó R. Novák Cs, Éhen Zs. Application of DSC and NIRS to study the compatibility of metronidazole with different pharmaceutical excipients. J Therm Anal Calorim. 2006;84:447-51.

12. Wesolowski M, Rojek B. Thermogravimetric detection of incompatibilities between atenolol and excipients using multivariate techniques. J Therm Anal Calorim. 2013;113:169-77.

13. Miller TW. Use of TG/FT-IR in material characterization. J Therm Anal Calorim. 2011;106:249-54.

14. Sasic S, Ozaki Y, editors. Raman, infrared and near-infrared chemical imaging. Hoboken: Wiley; 2010.

15. Rojek B, Wesolowski M, Suchacz B. Detection of compatibility between baclofen and excipients with aid of infrared spectroscopy and chemometry. Spectrochimica Acta Part A. 2013;116:532-8.

16. Jamrógiewicz M. Application of the near-infrared spectroscopy in the pharmaceutical technology. J Pharm Biomed Anal. 2012;66:1-10.

17. Johansson J, Pettersson S, Taylor LS. Infrared imaging of laserinduced heating during Raman spectroscopy of pharmaceutical solids. J Pharm Biomed Anal. 2002;30:1223-31.

18. Buckley K, Matousek P. Recent advances in the application of transmission Raman spectroscopy to pharmaceutical analysis. J Pharm Biomed Anal. 2011;55:645-52.

19. Bonawi-Tan W, Williams JAS. Online quality control with Raman Spectroscopy in pharmaceutical tablet manufacturing. J. Manufact Sys. 2004;23:299-308.

20. Hausman DS, Cambron RTh, Sakr A. Application of on-line Raman spectroscopy for characterizing relationships between drug hydration state and tablet physical stability. Int J Pharm. 2005;299:19-33.

21. Bakeev KA, editor. Process analytical technology. Chichester: Wiley; 2010.

22. Rowe RC, Sheskey PJ, Quinn ME. Handbook of pharmaceutical excipients. 6th ed. London: Pharmaceutical Press and American Pharmacists Association; 2009.

23. Szynkaruk P, Wesolowski M, Samson-Rosa M. Principal component analysis of thermal decomposition of magnesium salts used as drugs. J Therm Anal Calorim. 2010;101:505-12.

24. Silverstein RM, Webster FX, Kiemle DJ. Spectrometric identification of organic compounds. 7th ed. Hoboken: Wiley; 2005.

25. Skoog DA, West DM, Holler FJ, Crouch SR. Fundamentals of analytical chemistry. Belmont: Brooks \& Cole; 2004. 